\title{
Instructional Practices in Teaching Literature: Observations of ESL Classrooms in Malaysia
}

\author{
Gurnam Kaur Sidhu \& Chan Yuen Fook \\ Faculty of Education, Universiti Teknologi MARA \\ 40200 Shah Alam, Malaysia \\ E-mail: gurnamsidhu@salam.uitm.edu.my; yuenfook@hotmail.com
}

Sarjit Kaur (Corresponding author)

English Language Studies Section

School of Humanities, Universiti Sains Malaysia

11800 Penang, Malaysia

Tel: 60-4 653-2702 E-mail: sarjit@usm.my

\begin{abstract}
Literature is an expression of life through the medium of language and in the ESL classroom it is often seen as an authentic means of learning the target language. A literature-enriched curriculum not only helps learners improve their reading and writing skills but more importantly helps them internalise grammar and vocabulary. The many benefits of literature saw the implementation of the Contemporary Children's Literature (CCL) programme in all upper primary ESL classrooms in Malaysia four years ago. Using classrooms observations and interviews as research instruments, this paper critically examines the instructional practices of five Teaching English as a Second Language (TESL) teachers teaching Year 4 students in the state of Selangor and evaluates the various challenges faced by them in their ESL classrooms. Preliminary findings on the Contemporary Children's Literature programme revealed that teachers spent a lot of time on individual comprehension work with little emphasis given to comprehension instruction and higher order thinking skills. The integration of literary elements in the literature classrooms was also minimal and teachers lacked creativity as far as organising learning tasks were concerned. Nevertheless, the CCL programme offers great potential for enhancing English language learning among students. Policy makers and education leaders also need to take cognizance of related concerns, challenges and issues prevalent in Malaysian ESL classrooms.
\end{abstract}

Keywords: Instructional practices, Literature in the language classroom, Contemporary literature programme, Teacher education, ESL classrooms

\section{Introduction}

Literature is often said to be the 'window to the world.' It is a product of cultures that has a compendious store of information through which learners can gain insights as to the history, traditions and conventions of the target language (Carter \& Long, 1991a). By reading literary texts, learners can get discerning glimpses of a range of cultures and other useful insights that can help broaden one's worldview (Sidhu, 2003). In addition, literature fosters an understanding and appreciation of cultures and ideologies, which are different from the learners' native culture, which may be regarded as a 'standard' or 'norm'. According to Padmini (2009), such exposure stirs reflection and stimulates action as literature enables learners to understand, empathize and participate vicariously in a number of cultures. Through this, the tolerance aspect is both learnt and caught. More importantly, literature puts learners in touch with a range of emotional experiences and expressions that encourages self-reflection and the education of the whole person.

Literature is said to be fundamentally a study of language and literature is language in use and cannot be separated from language (Widdowson, 1985). Hill (1989) and a number of others researchers like Collie \& Slater (1987), Carter \& Long (1991b), and McRae (1991) point out that learners often read a literary text to enjoy a good story and the desire to go on reading despite linguistic difficulties motivates them to read on. They highlight that this motivation helps learners unconsciously learn the language. Furthermore, Sidhu (2003) and Savvidou (2004) add that the study of literature unconsciously enhances students' overall linguistic competency including their knowledge of syntax, morphology, semantics and phonetics.

Adding to this discourse, Collie and Slater (1989:5) state that literature also provides a rich context in which "individual lexical and syntactical items are made more memorable". Mahmud (1989:25) found that literature 
helped his students acquire "native-like competence in English". He added that it also exposed his students to the way the English linguistic system is used for communication and helped them improve their knowledge of syntax, morphology, semantics and phonetics. Gwin (1990:10) pointed out that it is only through literature that learners are exposed to the "subtle elements that go into the creation of what is called good writing". Chin (1991) elaborated that since literature exposes learners to a variety of writing styles, it would unconsciously help learners develop their own writing style. Carter \& Long (1989) concur and say that since learners do not want to bare their souls, literary tasks provide them a voice through which they can express themselves freely that is authentic. In a similar manner, Widdowson (1987) pointed out that reading should be seen as an interaction between a writer and a reader, which is mediated by the text. Since literary texts have implicit meanings, learners have to be trained to look for clues and signs so that they can 'tease out' unstated implications and assumptions. Moreover, as there is no one correct solution and interpretation, a class discussion on a particular issue in a text would generate genuine communication. Such discussions coupled with getting learners to tease out meanings while working with multiple ambiguities develop students' creative and critical thinking skills.

In the Malaysian context, a recent study conducted by Ali Ghani, Mohamed Abu Bakar, Sarina Salim \& Majeedah Mohd Shukor (2007:121) claim that through the literature component, learners are given the opportunity to discuss literary elements such as plot, character, setting, point of view, values, message and themes. They stress that deliberations on such aspects challenge learners to use their creative and critical thinking skills. According to Vethamani (2007), various questioning techniques should be viewed as strategies towards 'unlocking' literary texts and developing critical thinking skills among learners. Adding to this discourse, Stephens (2006) reiterates that positive critical and creative thinking skills can be nurtured using the Socratic Method when exploiting literary texts in the ESL classroom.

Literature is often said to represent the use of authentic materials in language instruction. Ibsen (1990) argued that authentic materials such as timetables, newspapers, letters and menus being used in the communicative classroom represent survival English without meaningful learning and knowledge of the target language. On the other hand, literary texts can be seen as a valuable complement to authentic materials, which provide genuine and undistorted language that can be managed in the language classroom. This 'comprehensible input' can only be obtained from literary texts.

The many advantages of literature are not without limitations. One of the main arguments against the use of literature relates to its literariness. Brumfit (1986) points out that literature, as resource in the ESL classroom is quite 'useless' as many of the second language learners do not possess the necessary linguistic and literary competency to handle the texts. Carter \& Long (1991b) added that cross-cultural differences along with the insufficient cultural knowledge of the target culture also lend a hand in the poor comprehension and appreciation of the text.

These problems and shortcomings can however be overcome with the use of Graded Renders. They are often seen as a useful introduction to extensive reading. Graded Readers are often seen as the first point of exposure to the realm of literature for the ESL/EFL learner. According to Hill (1986) grading is important if we want our learners to read original works in the future. The common controls used in graded readers are lexical control, structural control and content control. Livingstone et al. (1989:15) argued that current methodology supports the benefits of extensive reading through graded readers as they are simple, easy to carry and are "the only solution to problems when learners are faced with linguistic and literary competency".

Savvidou (2006) notes that Carter and Long put forward three main approaches used to teach literature, i.e. The Cultural Model, The Language Model and The Personal Growth Model. The Cultural Model represents the traditional approach that views the literary text as a cultural artifact where learners are required to explore and interpret the social, political and literary context of the text. This teacher-centred approach offers little opportunity for extended language approach. The Language Model uses the literary text to exemplify specific linguistic features as a focus for grammatical and structural analysis. This approach allows inadequate levels of engagement of the learner with the text. The Personal Growth Model attempts to bridge the gap between the cultural and the language model. It uses the text as stimulus for discussion in support of reflection and personal growth activities. What is perhaps needed is a more integrated method that takes into account all the three models proposed. According to Maley \& Duff (1989), the Integrated Model takes into account the linguistic, methodological and motivational aspects of teaching literature and can be adapted for all levels. Muhammed Abu Bakar \& Rosli Talif (2007) emphasize that in the Malaysian Children's Contemporary Literature Programme (CCLP) classrooms, a combination of both teacher-centred and student-centred approaches are encouraged for the critical reading of literary texts. 


\section{Background to the Study}

The many benefits of a literature-enriched curriculum have seen the inclusion of literature in a number of educational contexts. The inclusion of literature in the Malaysian ESL classroom is clearly articulated in the Malaysian Primary and Secondary English Language syllabus. In addition to that, all secondary school students were involved in the Class Reader Programme in 1990 and later in 1999 the teaching of literature became an integral part of the language syllabus. The literature component also became an assessment component for the two national examinations at the secondary levels in Malaysia - i.e. the Middle School Assessment (PMR) and Malaysian Certificate of Examination (SPM) which is taken by high school students in Year 9 and 11 respectively. In 2005, the literature component was extended to students in the primary schools through two programmes: the Contemporary Children's Literature and the Extensive Reading Programme. The main aims of these programmes are to inculcate the reading habit among students and to enable them to become independent readers. In 2004, the Malaysian Cabinet decided that Contemporary Children's Literature (CCL) be introduced in Years 4, 5 and 6 to help improve students' English language proficiency. The literature programme was also viewed as a platform to provide an early beginning to a foundation in literature to develop an understanding of other societies, cultures, values and traditions that will help them in their emotional and spiritual growth. It was also felt that a study of literature would help enhance students' linguistic ability.

The Contemporary Children's Literature (CCL hereafter) Programme was seen as a follow-up to The Structured Reading Programme for Year 1 and Year 2 students. The CCL programme was implemented in all Malaysian primary schools in 2005 beginning with students in Year 4. It was extended to Year 5 students in 2006 and to Year 6 students in 2007. The aims of the CCL programme are to help students improve their English by way of reading simple fiction. Furthermore the CCL aims to provide a continuum of learning abilities for the literature component introduced in secondary schools. The objectives of the CCL programme are as follows:

- To instill and inculcate the reading habit

- To enrich students' vocabulary and language content

- To enhance students' thinking skills

- To promote cultural understanding in the Malaysian context

- To improve students' English language proficiency

- To provide lively, enjoyable and high-interest readings

Under this intensive reading programme pupils will be encouraged to complete reading three prescribed texts per year. The contemporary literature texts consist of works written after 1900. They also deal with everyday or current issues that children face in their everyday lives. The texts selected included graded readers that consisted of short stories and poems. Different sets of texts are allocated for National and National Type Primary Schools. In the National schools, teachers were required to allocate one period a week for the teaching and learning of the literature component under the CCL programme. For the National Type Primary Schools (Chinese and Tamil vernacular schools), literature is taught once a fortnight.

Under the CCL programme, students are required to do the reading at home and discuss the book in class. Teachers are required to prepare and facilitate activities for three phases (Pre Reading, While Reading and Post Reading) to help keep track of students' understanding and to help them to consolidate and reflect on what they have read. While reading, teachers are also encouraged to bring students' attention to both language use and literary devices such as the plot, the setting, the characters, the themes, messages and moral values. Teachers are also encouraged to utilize the reading texts for school based oral assessment and portfolio assessment activities.

\section{Research Design}

The main aim of this study was to investigate how the CCL programme was implemented in the Malaysian Primary ESL classrooms. The implementation focused on one main aspect - i.e. the instructional practices of teachers teaching in the CCL programme.

A descriptive research methodology was employed and the two main instruments used to collect data were classroom observations and interviews. The sample population used in this study consisted of five randomly selected schools located in Shah Alam in the state of Selangor in Malaysia. In each school, one TESL teacher teaching a Year 4 class under the CCL programme was randomly selected, after securing permission from the school principals and the state education department. Hence, the sample population consisted of five TESL trained teachers teaching Year 4 ESL classrooms. 
Each ESL classroom was observed four times. In this study, the five teachers are referred to as Teacher A, Teacher B, Teacher C, Teacher D and Teacher E. The first observation for each class was not taken into consideration to avoid what researchers call the researcher's paradox - i.e. the teacher's language and the students' responses may be affected when they know they are being observed. Only data from the second, third and fourth observations were used for this study. All the classroom observations were audio recorded and field notes were taken to provide additional information on the classroom context. At the end, a total of 15 classroom observations were used for purposes of data analysis. The semi-structured interviews conducted with the classroom teachers looked into aspects such as teacher readiness, teacher knowledge and teacher perceptions of the CCL programme.

\section{Findngs and discussion}

\subsection{Demographic Information}

An analysis of the population sample of this study indicated that four out of the five respondents were females. Two of the teachers were below the age of 30 while another two were below the age of 40 . The remaining teacher was 53 years old. In terms of academic qualifications, four of the respondents possessed a Teaching Diploma in TESL while another was a TESL graduate with a university degree.

The semi-structure interviews revealed that only one of the teachers had a background in literature while another two teachers indicated that they had attended literature courses organized by the Ministry of Education, Malaysia. The average number of literature courses attended by the respondents was one. The average number of hours these teachers spent on reading activities per week was 1.63 hours.

\subsection{Instructional Practices}

The following section describes the instructional practices of the five teachers teaching Year 4 CCL classrooms.

Firstly, it was observed that all five teachers spent a major portion (78.0\%), of classroom time addressing the whole class (Table 1). In all the observed lessons, addressing the class comprised sessions where either the teacher or the students read the text aloud or Q\&A (question and answer) sessions. Students carrying out seatwork accounted for another $15.0 \%$ of the time. During seatwork, students were required to do work on an individual basis. It consisted of completing worksheets. On the other hand, activities requiring students to work in pairs or groups accounted for the remainder $7.0 \%$. Moreover, only Teacher E and Teacher $\mathrm{C}$ carried out pair work and only Teacher E and Teacher B had pair work activities in their CCL classrooms.

\section{INSERT TABLE 1 HERE}

The Integrated Primary School English Language syllabus that is used in all Malaysian schools is a skills-based syllabus. It encourages TESL teachers to integrate all the four skills of listening, speaking, reading and writing in their everyday ESL lessons. Therefore, one feature that was investigated in the CCL classroom was the amount of time spent on each of these skills. The results obtained are presented in Table 2 below:

\section{INSERT TABLE 2 HERE}

The findings indicated that a lot of emphasis was spent on reading and writing skills while speaking and listening skills took a back seat. In fact listening activities were hardly observed in the CCL classrooms of Teacher A and Teacher D. Speaking activities that required students to discuss issues in the text accounted for approximately $25.0 \%$ of classroom time. In fact speaking activities that did focus on the discussion of issues raised by the text was only seen in Teacher E's CCL classroom. The rest of the classroom speaking activities were based mainly on one-liners, which required to students to answer questions posed by the teachers.

Reading was one activity that received much emphasis in all five CCL classrooms. It included activities such as reading the text aloud and reading aloud questions or dialogues in role-play activities. Both Teacher $\mathrm{A}$ and Teacher $\mathrm{C}$ spent a lot of classroom time reading the literary text. At times it looked more like a Reading Aloud classroom. Interview sessions with both teachers revealed that they carried out reading aloud activities as they felt their learners possessed limited language proficiency. They highlighted that their students did not read the text at home and therefore they were compelled to conduct reading aloud sessions. They also added that their students were not able to read and understand the text if they were to read silently. Both teachers were of the opinion that reading aloud would help improve their students' comprehension and pronunciation abilities.

Writing was one of the most popular activities observed in all the five classrooms. The writing activities centred on answering questions that teachers posed through the use of photocopied worksheets. When these writing tasks were analysed, the findings revealed that students were engaged only in tasks that required short responses. In all the five CCL classrooms, there was no writing task that required students to give their personal responses. 
Interview sessions with the teachers revealed that teachers felt they had no time for personal responses or more challenging writing tasks as time for CCL lessons was limited to less than half an hour after logistics issues were ironed out in classroom management. None of the five teachers interviewed were of the opinion that writing tasks related to CCL could be taken and explored in their everyday ESL lessons.

Classroom observations indicated that all five teachers spent a great deal of time on three main types of classroom activities - i.e. reading activities, language-based activities and comprehension activities. Reading activities, as mentioned earlier, focused mainly on reading aloud excerpts from the literary text whilst language-based activities included grammar and vocabulary activities. Comprehension activities consisted of activities where students were required to answer comprehension questions based on the text either orally or in the written form to gauge their understanding of the text. A full analysis and comparison of these three activities is presented in Table 3 .

\section{INSERT TABLE 3 HERE}

Since a lot of time was spent on comprehension activities, further analysis at the micro level was carried out. Analysis was carried out on the Q\&A sessions and the questions asked both orally and in the written form. The questions were analyzed based on the six categories put forward by Bloom's Taxonomy - i.e. knowledge, comprehension, application, analysis, synthesis and evaluation. The findings indicated that lower order thinking skill (LOTS) questions such as comprehension (45.0\%), knowledge (40.0\%) and application (5.0\%) questions accounted for $90.0 \%$ of all the questions posed to the students. These questions referred to mainly literal and surface level content questions which tested the students' comprehension of the story. Given below are some examples of the questions posed during the classroom observations. For instance, in observation 3C (Teacher C, Observation 3), the following were some of the lower order thinking skill (LOTS) questions posed when she was discussing the story "The Bell' from the text Tales and Tails:

- Who found the bamboo bell?

- What happened when the bell rang?

- What did the rich man get his servant to do?

- Who stole the bell?

Data obtained also revealed that higher order thinking skills (HOTS) questions accounted for only $10.0 \%$ of the questions posed to students from the 10 observations. Higher order thinking questions like questions on analysis (3.0\%) could help improve students' inferencing skills while synthesis (3.0\%) and evaluative (4.0\%) questions could provide opportunities for students to think critically. Such opportunities were hardly seen in the CCL classroom observations. Teacher E and Teacher B who were observed teaching the literary text The Little Blue Boy posed the following HOTS questions:

- If you were the Blue Boy would you go out and play with other children?

- How would you feel if other people made fun of you?

- Which character do you like best? Tell me why you like the character.

Classroom observations indicated that there were a number of instances where there were opportunities for teachers to challenge their pupils to think and demand them to use their skills in analyzing, synthesizing or evaluating. Given below is an excerpt taken from Teacher D's classroom that displayed such a moment:

Teacher D: Was Tanya's diary on her bed?

Pupils: No.

Teacher D: Was it under her bed?

Pupils: No

Teacher D Where was Tanya's diary?

Pupils: (in the) dining room.

Teacher D: Who found it?

Pupils: Her mother.

Teacher D: Okay who put it there?

Pupils: Tanya

Teacher D: Okay, now complete the exercise. 
The above excerpt illustrates that here was a potential moment where the teacher could further probe into students' interpretation of the situation. The teacher could pose a question such as "what does this show / indicate about Tanya" or 'what lesson can we learn from this incident / story?' Such situations prevailed in almost all the CCL classrooms but most of the teachers chose to focus only on questions converging on students' worksheets taken from revision or commercially prepared guidebooks. Observations indicated that the teachers also did not encourage critical reading. The sessions revealed that teachers did not encourage students to carry out activities such as cross-referencing. There were also limited instances where the teachers encouraged students to sit and discuss issues or related events and experiences that had connections to students' personal experiences. As indicated above, classroom observations revealed a number of viable situations but teachers did not exploit those moments.

Since a large amount of time was spent on comprehension activities, further analysis was carried out on the kind of comprehension activities carried out in the CCL classrooms. As a result, the comprehension activities were further analyzed according to Durkin's (1979) teacher-behaviour categories i.e. comprehension for application, assessment, assignment, help with assignment, instruction, prediction, preparation and review of instruction. The findings are presented in Table 4.

\section{INSERT TABLE 4 HERE}

The findings indicate that in comprehension activities, teachers spent very little time discussing a number of comprehension activities that could help develop their students' comprehension activities. Some of these activities include Comprehension Instruction (where a teacher does something to help students understand a task) and Comprehension Preparation (where a teacher carries out activities for reading before it begins); it includes activities such as discussing new vocabulary, asking questions to motivate students or providing background information.

The data shows that most of the time in the teacher-behaviour recorded for comprehension activities was accorded to comprehension assessment. This refers to an instance where the teacher questions students to assess something they have read. This behaviour displayed a record of $67.0 \%$ of all comprehension behaviours. This finding is also similar to findings in Durkin's (1979) study, where teachers are seen as mere mentioners of assignment givers. They also act as assignment checkers and interrogators. Although teachers spent a large amount of time assessing, little help was provided for comprehension - help with assignment accounted for a mere $5.0 \%$ of the total time allocated for comprehension activities. Teachers appeared to focus their lessons on giving and checking students' performances in comprehension assignments.

One of the aims of the CCL programme is to provide a continuum for the literature component introduced in secondary schools. Therefore, one of the aspects analyzed during classroom observations was the inclusion of literary elements such as the study of plot, character and themes. Findings indicated that the introduction of literary elements was minimal. Nevertheless, more emphasis was given to the study of plot $(80.0 \%)$ when compared to other literary elements. Activities on plot usually addressed aspects such as the sequence of events and the study of both main and sub plots. Approximately $10.0 \%$ of the time spent on literary elements focused on character study but little emphasis was given to attitudes and beliefs, kinds of relationship, actions and reactions, interactions with one another and character development and their roles and functions. The remaining $10.0 \%$ addressed the aspect of moral values. Even so, both aspects were not well explored or discussed in the CCL classrooms. Other literary elements such as the study of setting, theme and literary devises such as similes were not observed in all the 10 lessons observed in this study. Interview sessions with the respondents revealed that teachers acknowledged that the integration of literary elements was minimal because in their opinion the aim of CCL was to motivate and inculcate the reading habit among their students. Furthermore, Teachers A, B and D felt their students may not be able to handle the aspect of literary elements. Teachers A, B and C also claimed that they themselves fell short in that area and required more training.

Classroom observations also indicated that some teachers took the opportunity to use CCL lessons to integrate study skills. Teachers B, D and E were seen making it a point to encourage their pupils to use the dictionary and in Teacher E's classroom, conscious effort was made by the teacher to encourage them to use the dictionary and the thesaurus for language based activities. The following excerpt was taken from Teacher C's classroom:

Teacher C: Okay number 1 - What is the title?

Pupil A: Tanya, Tidy Your Room

Teacher C: Yes, now remember when you write the answer what must you use?

Pupil B: $\quad$ Big letters 
Teacher C: Yes, you must use capital letters. Remember we use capital letters for the names, places, people and titles.

The following excerpt is taken Teacher A's CCL classroom:

Teacher A: What is a tunnel? Take out your dictionary and find the meaning.

Pupil A: terowong (Malay word meaning 'tunnel')

Teacher A: Yes, tunnel is terowong. So Tanya imagined she was in a terowong. Now what did she see there. Dia nampak apa?

One interesting aspect observed during classroom observations was the rather extensive use of code switching between English and Bahasa Malaysia (the national language) by all teachers in this study. Code switching in this study refers to an instance when the teacher or student alternates from English to Bahasa Malaysia with another bilingual speaker who is able to speak both languages. Since most Malaysians are mainly bi and tri lingual, the translation method was seen as a common method in addressing certain aspects such as giving the meaning of difficult words, or giving explanations of texts or logistics issues. Given above is an example of code switching used by the teacher and students to explain the meaning of the word 'tunnel'. The examples below show how code switching is used to give explanations or clarifications:

Teacher D: What can you see on cover of book? You don't want to list all. Tak payah tulis banyak - tiga cukup (meaning: You don't have to write much, list three is sufficient)

Teacher E: What is the story called?

Pupil X: The Little Blue Boy

Teacher E: Yes, say in one sentence, guna ayat penuh (meaning - 'use a complete sentence') Say: “The story is called The Little Blue Boy"

During the interview sessions, teachers were asked why Bahasa Malaysia was used rather extensively during their CCL lessons. The teachers cited students' limited proficiency as the main reason as to why they resorted to code switching.

However, findings indicated that teacher competency could perhaps be another reason for this inclination towards code switching. Given below are some examples of teachers' limited proficiency:

Teacher A: What is illustrator? A illustrator is people who draw picture. A drawer, pelukis (meaning an artist).

Teacher B: Who is clean the room at the end?

Teacher C: In this story, you like which person? Tell me why you likes the person

Teacher D: All those who finis can now give back the book . . . put on my table in the front

A final observation related to the use of materials in the CCL classroom. Most of the teachers interviewed agreed that materials prepared by the Ministry of Education (MOE) were suitable and useful. Nevertheless, not one of the 5 teachers observed used the MOE materials. All 5 teachers agreed that more than $95.0 \%$ of their work and exercises were taken from reference and guidebooks published by commercial publishers. Of the five teachers, three teachers (Teachers A, C and E) had a prescribed workbook for the CCL lessons. In fact Teacher C and E depended heavily on the exercises in the workbook. For Teacher C, the CCL lessons just meant doing the workbook exercises page by page.

Interview sessions with the teachers further revealed that these workbooks and reference books published by commercial firms were the main source of reference for all five teachers in this pilot study. For Teachers B and $\mathrm{D}, 90.0 \%$ of the classroom exercises were also taken from workbooks. The teachers also admitted that they did little reference on their own. All five teachers admitted that due to time constraints, they did not prepare their own worksheets. None of them used the Internet to get information on the teaching and learning of literature for children. Two teachers (Teacher C and D) claimed that they were not technology savvy whilst the other three felt they did not have the time and stressed that there were sufficient materials in the open market.

Under the CCL programme, teachers are encouraged to carry out activities based on the following model - i.e. pre-reading, while-reading and post-reading activities. Classroom observations however indicated that only one teacher (i.e. Teacher E) used this model. The remaining four hardly used any set induction activities to motivate their students to the day's lesson. They also failed to take any conscious steps to carry out before / during/ after reading activities. The CCL programme also encourages teachers to get their students to keep portfolios for their 
Literature classes. Only Teacher A practiced this and even though her students had low English proficiency, there were two pieces of work in the students' portfolio.

\section{Teachers' perceptions of the Contemporary Children's Literature programme}

Interview sessions with the five teachers revealed that all of them were aware of the aims and objectives of the CCL programme and were able to vocalize the benefits that literature could bring into their ESL classroom. The teachers felt that CCL could help improve their students' language proficiency. They also voiced their support and belief in the programme and rated their level of knowledge of the programme close to $80.0 \%$. Nevertheless, teacher confidence stood at $68.0 \%$ and four out of the five teachers felt they needed additional training in literature.

The respondents agreed that the Readers provided under the CCL programme were suitable and appropriate to their students' linguistic competency. Teachers A and B however felt that some books were slightly challenging for their weaker students. The Readers provided by the MOE were deemed suitable but teachers voiced concern that there were insufficient books for all the students. Hence, teachers took the liberty of making photocopies of the Readers. According to Teacher B, "photocopied books are not in colour and therefore are rather unattractive." She added that this aspect demotivated some of her students were and make them feel reluctant to read them.

Where instructional practices were concerned, all five respondents were able to articulate what constituted good teaching practice. All agreed that teaching has to be student-centred. Teachers A, B and C admitted that their classrooms were not student-centred as their students were very weak in English and it was difficult to get their students to participate in classroom discussions. Hence, they were aware that their classrooms were indeed teacher-centred. All the respondents were aware of the importance of pre, while and post reading activities.

Interview sessions also looked into the main challenges that teachers faced in implementing the CCL programme. Students' limited proficiency and insufficient Readers were among the main issues that the teachers raised. Insufficient supplementary materials and insufficient training were also issues of concern raised by these teachers.

\section{Implications and recommendations}

Classroom observations indicated that the instructional practices of teachers entail them spending a lot of classroom time addressing the whole class. Teachers also paid little emphasis on both co-operative and collaborative learning. Further analysis revealed that Q\&A comprehension was the main activity in the CCL classroom. When these interactions were analyzed, findings indicated that very little time was spent on comprehension instruction as teachers focused classroom time on assessments and giving assignments. Very little assistance was provided for help with classroom assignments. Besides that, photocopied worksheets taken from commercial workbooks seemed to be the only resource material used by teachers in the teaching and learning process. Furthermore, the Reader was seldom used, referred to or exploited for study in the CCL classroom and the study of literary elements was minimal. All these findings indicate that perhaps the MOE needs to reexamine the nature of the implementation of the CCL programme. The following are some implications, which may facilitate the achievement of the aims set out by the ministry.

First and foremost, teachers need to be introduced to models of good teaching. Such a move calls for effective training sessions to be conducted. Perhaps it is time to reconsider the Cascade Training Model that is currently being used as a basis for in-service training programmes for MOE teachers. Models of good teaching can also be shown through the use of video or CD clippings of actual or simulated training sessions. In-service training sessions should also include creative teaching techniques and currently advocated methodology that is both learner-centred and task-centred.

Furthermore, teachers should also be given training in literature as four out of the five respondents in this study felt they needed exposure to the teaching and learning of literature. These teachers need more help and support to boost their confidence in implementing CCL effectively. Perhaps they too need to be taken along the path of literature from literal comprehension of texts to active engagement with literary elements such as character, plot, themes and setting.

Findings of this study also indicated that the main resource materials used by teachers are worksheets taken from workbooks published in the open market. Teachers should perhaps look into the alternative of setting up a portal for the teaching of CCL in Malaysian schools. Such a portal can encourage teachers not only to share their experiences and challenges but more importantly materials that have achieved success in their classroom. 
Finally, teachers must be encouraged to be more reflective of their instructional practices. This can be carried out if teachers engage in action research. Teachers should not only record or audio-tape their own lessons but peer evaluation should be part and parcel of the teaching and learning process. Such measures can, in the long run, provide useful insights into their classroom practices such as the use of code switching and teacher linguistic competency. Teachers' reflective measures will hopefully lead to the effectiveness and improvement of classroom instruction.

\section{Conclusion}

The Contemporary Children's Literature programme was brought into the Malaysian primary ESL classroom on a 'sea of faith.' The programme hopes to improve students' English language proficiency, instill and inculcate the reading habit and promote cultural understanding in the Malaysian context. Such noble aspirations can only become a reality if classroom instructional practices are in tandem with the aims and objective outlined by the CCL programme.

Findings of this study indicate that classroom instructional practices leave much to be desired. Classroom practices reveal that great emphasis is given to Q\&A comprehension activities and teachers are seen more as examiners and assignment givers with little opportunity provided for classroom or group discussion of issues raised in texts. Therefore, adequate and proper training has to be provided to teachers to ensure they are confident enough to handle the needs of the programme and make this programme a success. Nevertheless, the seeds have been sown and the onus now lies in the hands of the teachers to make it a success. To make the Children's Contemporary Literature Programme the implementers (i.e. the TESL teachers) need the support not only of the school administrators but also parents and stakeholders so that the students can reap the true benefits of a literature enriched language curriculum.

\section{References}

Ali Abdul Ghani, Mohamed Abu Bakar, Sarina Salim, Majeedah Mohd. Shukor. (2007). Implementation of the English Language Literature Component for Secondary Schools: An Impact Study. Jurnal Penyelidikan Pendidikan 9, 121-141.

Bloom, B.S. (1956). Taxonomy of Educational Objectives: The Classification of Educational Goals. New York: Longman.

Brumfit, C.J. \& Carter, R.A. (1986). Literature and Language Teaching. Oxford: Oxford University Press.

Carter, R.A. \& Long, M.N. (1991a). Web of words: Exploring Literature through Language. Cambridge: Cambridge University Press.

Carter, R.A. \& Long, M.N. (1991b). Teaching Literature. Cambridge: Cambridge University Press.

Brumfit, C. (1985). Language and Literature Teaching. Oxford: Pergamon Press Ltd.

Chin, M. (1991). Literature in the Language Classroom. In Compendium: A Handbook for ELT Teachers. Kuala Lumpur: Malaysian Ministry of Education, 63-72.

Collie, J. \& Slater, S. (1989). Literature in the Language Classroom. Cambridge: Cambridge University Press.

Durkin, D. (1979). What Classroom Observations Reveal about Reading Comprehension Instruction. Reading Research Quarterly. XIV(4),483-533.

Gwin, T. (1990). Language Skills through Literature. FORUM XXVIII (3), 10-13.

Hill, J. (1986). Teaching Literature in the Language Classroom. London: Macmillan.

Ibsen, E. B. (1990). The Double Role of Fiction in Foreign Language Learning: Teaching a Creative Methodology. English Teaching Forum. XXVIII (3), 2-9.

Kementerian Pelajaran Malaysia. (2004). Contemporary Children's Literature: Objectives, Principles and Guidelines. Kuala Lumpur: Curriculum Development Centre.

Livingstone, C., Pike, H., Tadman, J., Tunnacliffe, D. \& King, J. (1989). The Longman Guide to Graded Reading. UK: Longman Group Ltd.

Maley, A. \& Duff, A. (1989). The Inward Ear-Poetry in the Langauge Classroom. Cambridge: Cambridge University Press.

Mahmud, H. S. (1989). From Language to Literature in University English Departments. English Teaching Forum. XXVII (3), 25-27. 
Mohamed Abu Bakar \& Rosli Talif (2007). Children's Literature: Practice in the Primary Classroom. In Rosli Talif \& Jariah Mohd. Jan. (Eds). Understanding Children's Literature. Petaling Jaya: Sasbadi MELTA ELT Series, 22-31.

Padmini, P. (2009). "Why" and "How" of Literature in the Language Classroom. Language in India. 4(3), 40-44.

Savvidou, C. (2004). An Integrated Approach to Teaching Literature in the EFL Classroom. Accessed on 13 January 2009, from http://iteslj.org/ Techniques/ Savvidou-Literature.html.

Sidhu, G.K. (2003). Literature in the Language Classroom: Seeing Through the Eyes of the Learner. In M.E. Vethamani \& G. Subramaniam (Eds). Teaching of Literature in ESL/EFL Contexts. Petaling Jaya: Sasbadi MELTA ELT Series, 88-110.

Stephens, K.R. (2006). Nurturing Critical Thinking. The Editor's View, 6(4), 1364-1375.

Vethamani, M.E. (2007). Reading Literary Texts. The English Teacher, Vol XXXVI, 20-33.

Widdowson, H. G. (1985). The Teaching, Learning and Study of Literature. English in the World. Cambridge: Cambridge University Press.

Table 1. Percentage of Classroom Time Spent of Classroom Activities

\begin{tabular}{|l|c|}
\hline Classroom Activities & Percentage of Classroom Time Spent (\%) \\
\hline Whole Class & $\mathbf{7 8}$ \\
\hline Seat Individual Work & $\mathbf{1 5}$ \\
\hline Pair Work & $\mathbf{5}$ \\
\hline Group Work & $\mathbf{2}$ \\
\hline
\end{tabular}

Table 2. Percentage of Classroom Time Spent on Language Skills

\begin{tabular}{|l|c|c|c|c|}
\hline Teacher & Listening & Speaking & Reading & Writing \\
\hline Teacher A & - & 12.5 & 45.8 & 41.7 \\
\hline Teacher B & 9.5 & 38.1 & 24.9 & 27.5 \\
\hline Teacher C & 8.6 & 23.8 & 35.0 & 32.6 \\
\hline Teacher D & - & 26.4 & 27.8 & 45.8 \\
\hline Teacher E & 12.7 & 25.0 & 26.6 & 35.7 \\
\hline Average & $\mathbf{6 . 2}$ & $\mathbf{2 5 . 1}$ & $\mathbf{3 2 . 0}$ & $\mathbf{3 6 . 7}$ \\
\hline
\end{tabular}

Table 3. Percentage of Classroom Time Spent of on Three Main Activities

\begin{tabular}{|l|c|c|c|}
\hline Teacher & Reading Activities & Language-Based Activities & Comprehension Activities \\
\hline Teacher A & 45.8 & 9.5 & 44.7 \\
\hline Teacher B & 24.9 & 18.4 & 56.7 \\
\hline Teacher C & 35.0 & 6.4 & 58.6 \\
\hline Teacher D & 27.8 & 10.9 & 61.3 \\
\hline Teacher E & 26.6 & 20.8 & 52.6 \\
\hline Average & $\mathbf{3 2 . 0}$ & $\mathbf{1 3 . 2}$ & $\mathbf{5 4 . 8}$ \\
\hline
\end{tabular}

Table 4. Percentage of Classroom Time Spent on Types of Comprehension Behaviours based on Durkin's 8 Categories for Teacher Behaviour

\begin{tabular}{|l|c|}
\hline Teacher-Behaviour Category & Percentage of Classroom Time \\
\hline Comprehension - Instruction & $05 \%$ \\
\hline Comprehension - Application & $03 \%$ \\
\hline Comprehension - Assessment & $67 \%$ \\
\hline Comprehension - Assignment & $09 \%$ \\
\hline Comprehension - Preparation & $06 \%$ \\
\hline Comprehension - Review of Instruction & $05 \%$ \\
\hline Comprehension - Prediction & N.O. \\
\hline Comprehension- Helps with assignment & $5 \%$ \\
\hline
\end{tabular}

$$
\text { (N.O. = not observed })
$$

